\title{
APLIKASI PEMBAYARAN ADMINISTRASI SANTRI TERINTEGRASI SMS GATEWAY (STUDI KASUS PADA PONPES DARUSSALAM DUKUHWALUH)
}

\author{
Rizki Wahyudi ${ }^{1}$, Krisna Rhinaldi ${ }^{2}$ \\ ${ }^{1}$ Teknik Informatika, STMIK Amikom Purwokerto \\ ${ }^{2}$ Sistem Informasi, STMIK Amikom Purwokerto \\ J1. Letjen Pol Sumarto Watumas Purwanegara Purwokerto, Banyumas 53123 \\ Email : rizkiw@amikompurwokerto.ac.id, krisnarinaldi@gmail.com
}

Submitted: 02-01-2018, Reviewed: 06-01-2018, Accepted 10-01-2018

http://dx.doi.org/10.22202/jei.2017.v4i2.2940

\begin{abstract}
ABSTRAK
Penelitian ini bertujuan untuk membuat Aplikasi pengolahan data administrasi santri yang terintegrasi SMS Gateway, Pengolahan data dalam proses pembayaran administrasi santri masih dilakukan secara konvensional menyebabkan beberapa permasalahan diantaranya terjadi redudansi data yang terdapat pada laporan pembayaran, kesulitan mencari arsip pembayaran yang sudah dilakukan santri, Agar aplikasi dapat dikembangkan dengan terukur, maka digunakan Metode pengembangan sistem model Waterfall dengan tahapan analisis, desain, pengodean, pengujian. Pengujian dilakukan dengan dua pendekatan Alpha Testing dan Beta Testing. Alpha Testing merupakan pengujian yang dilakukan di sisi pengembang untuk menguji fungsional sistem menggunakan metode Black box, hasil pengujian Alpha Testing semua fungsional sistem berfungsi dengan baik, dan Beta Testing dilakukan menggunakan metode kuesioner untuk menguji sistem pada pengguna akhir berkaitan dengan kelayakan aplikasi, di dapat prosentasi 95,5\% pengguna setuju sistem telah layak di implementasikan. Kata kunci: Aplikasi, Pembayaran, Administrasi Santri, SMS Gateway, Waterfall.
\end{abstract}

\section{ABSTRACT}

This research aims to make the application of administrative data processing santri integrated SMS Gateway, Data processing in the process of payment santri administration is still done manually some data that occur redundant data contained in the payment report, the difficulty of looking for payment that has been done santri, the application to be developed with measurable, ie. Waterfall model development method by completing the analysis, design, coding, testing. Testing is done by measuring Alpha Testing and Beta Testing. Alfa Testing is a test done on the developer side to test the system functionality using Black Box method, Alfa test results in Functional system test well, and Beta Testing is done by using questionnaire method to test the application on the user, the percentage can be $95.5 \%$ of users agree the system is feasible to implement.

Keywords: Applications, Payments, Administrative Services, SMS Gateway, Waterfall.

\section{PENDAHULUAN}

Pondok Pesantren (PONPES) Darussalam merupakan lembaga pendidikan nonformal berbasis pendidikan agama islam yang sedang mengalami perkembangan, dalam kegiatannya PONPES melakukan beberapa pengelolaan data salah satunya administrasi santri. Administrasi santri merupakan hal penting untuk dikelola dengan baik, karena jika tidak di kelola dengan baik akan menimbulkan permasalahan dalam kegiatan dan proses belajar mengajar di PONPES Darussalam. 
Kegiatan administrasi merupakan serangkaian kegiatan yang dilakukan oleh sekelompok orang dalam melakukan suatu kerjasama guna mencapai tujuan tertentu. Agar manajemen dapat berjalan dengan efektif dan efisien untuk pencapaian dari sasaran-sasaran organisasi dapat dilakukan melalui perencanaan pengorganisasian, kepemimpinan dan pengendalian sumberdaya organisasi. Dengan demikian kegiatan administrasi akan berjalan lancar dengan adanya pengelolaan yang baik (Rudiyanto, 2014).

Pembayaran administrasi PONPES Darussalam meliputi pencatatan dan laporan transaksi pembayaran seperti iuran bulanan atau Syahriyah, pendaftaran santri baru, pembayaran Jariyah, pembayaran kartu tanda santri, pembayaran jas almamater, Haflah santri baru, pembayaran uang makan, dan pembayaran listrik (jika santri membawa laptop) yang saat ini masih dilakukan dengan cara konvensional. Ditambah lagi setiap tahunnya santri pada PONPES Darussalam terus bertambah. Mayoritas santri adalah Mahasiswa dan Pelajar. Berikut data santri dari tahun 2016 sampai Januari 2018.

Tabel 1. Data Santri Putra Putri

\begin{tabular}{llll}
\hline \multirow{2}{*}{ Tahun } & \multicolumn{2}{l}{ Data Santri } & \multirow{2}{*}{ Jumlah } \\
\cline { 2 - 3 } & Putra & Putri & \\
\hline 2016 & 125 & 115 & $\mathbf{2 4 0}$ \\
\hline 2017 & 170 & 135 & $\mathbf{3 0 5}$ \\
\hline 2018 & 202 & 170 & $\mathbf{3 7 2}$ \\
\hline
\end{tabular}

Pada Tabel 1. data santri putra dan putri tahun 2016 sampai tahun 2018 menunjukan semakin bertambah setiap dari tahunnya, maka aktifitas pengelolaan administrasi semakin banyak dan kompleks membutuhkan penanganan yang baik dan terstruktur. Sementara pengelolaan administrasi santri pada PONPES Darussalam selama ini masih dilakukan secara konvensional yaitu mengolah administrasi menggunakan Microsoft Office Excel, lalu di catat ke dalam buku besar yang bertujuan untuk mengarsipkan kegiatan yang telah dilakukan dalam mendata administrasi santri dan pada saat perekapan harus memilah-milah data terlebih dahulu untuk dijadikan laporan administrasi. Beberapa permasalahan diantaranya terjadi masalah redudansi data (data ganda) yang terdapat pada laporan pembayaran, kesulitan dalam mengakses data ketika akan melakukan proses pembayaran terlebih dahulu harus mencari satu persatu data santri pada buku besar untuk diarsipkan sebagai laporan, serta terdapat inkonsistensi data berupa data pembayaran pada kartu pembayaran santri berbeda dengan laporan pembayaran, sehingga akan menimbulkan data yang tidak akurat serta tidak konsisten pada laporan pembayaran santri.

Penelitian Saleh (2017) mengenai pembayaran administrasi keuangan berbasis desktop, dapat menangani masalah proses pelayanan untuk administrasi keuangan yang lebih baik di madrasah, sehingga penyampaian laporan keuangan yang dibutuhkan dapat dilakukan secara cepat dan tepat. Pada penelitian tersebut sudah dihasilkan sebuah sistem pembayaran yang terkomputerisasi. Penelitian lainnya menyatakan bahwa penting untuk mencari solusi dalam peningkatan layanan administrasi salah satunya dengan merancang dan membangun sistem (Anshori, Yosi, Fibrian, \& Zainal, 2008).

Selain pengolahan administrasi santri, pada PONPES Darussalam Dukuhwaluh juga mengalami kendala Penyelewengan pembayaran yang dilakukan santri. Berdasarkan informasi bendahara, beberapa santri yang menunggak diakibatkan uang pembayarannya digunakan untuk kepentingan pribadi, Orang tua santri tidak mengetahui perihal masalah tersebut. Selama ini pemberian surat informasi tunggakan yang diberikan kepada orang tua melalui santri tidak efisien, untuk mengatasi ini dapat menggunakan media SMS (Short Message Service) Gateway yang terintegrasi dengan sistem.

SMS merupakan media yang efisien untuk mengirim dan menerima pemberitahuan penting. Meskipun penggunaan aplikasi massanger seperti Blackberry Massanger, Whatsapp, LINE, WeChat sedang melesat, SMS masih tetap menjadi pilihan dalam bertukar informasi. SMS merupakan fitur 
yang pasti ada pada setiap ponsel. Semua ponsel memiliki fitur SMS, tidak peduli apakah ponsel didukung layanan 3G, touchscreen, dual SIM card, dan jenis ponsel smartphone atau bukan. SMS lebih kompatibel dengan semua jenis ponsel. Dengan adanya peningkatan kebutuhan akan informasi dan komunikasi, SMS Gateway hadir sebagai media penyedia informasi berbasis SMS. Penggunaan SMS Gateway populer dikalangan instansi pemerintah dan akademik.

SMS Gateway dinilai praktis dan efektif. Berdasarkan perilaku pengguna ponsel, apapun jenis pesan yang masuk, pasti akan dibuka dan dibaca sehingga pesan tersampaikan dengan cepat. Selain itu, Hampir semua wali santri memiliki ponsel serta mampu membaca SMS, sehingga dengan adanya sistem yang terintegrasi SMS Gateway ini wali santri dapat memantau dan mengetahui informasi status pembayaran administrasi anaknya.

\section{METODOLOGI PENELITIAN}

Pengembangan sistem berkaitan dengan validitas dan reabilitas hasil penelitan yang diperoleh. Metode pengembangan sistem yang diterapkan, yaitu model Waterfall. Model Waterfall sering juga disebut model sekuensial linier (sequential linear) atau alur hidup klasik (classic life cycle). Model Waterfall menerapkan pendekatan siklus hidup perangkat lunak secara sekuensial atau bertahap dimulai dari analisis, desain, pengodean, pengujian (Rosa \& Shalahudin, 2013). Model Waterfall mudah diterapkan dan kemungkinan adanya perubahan kebutuhan selama pengembangan perangkat lunak kecil. Hal positif dari model Waterfall adalah struktur tahap pengembangan sistem jelas, dokumentasi dihasilkan di setiap tahap pengembangan, dan sebuah tahap dijalankan setelah tahap sebelumnya selesai dijalankan. Sehingga tidak terjadi tumpang tindih dalam pelaksanaan (Lutfi \& Wahyudi, 2017). Tahap Model Waterfall dapat dilihat pada Gambar 1:

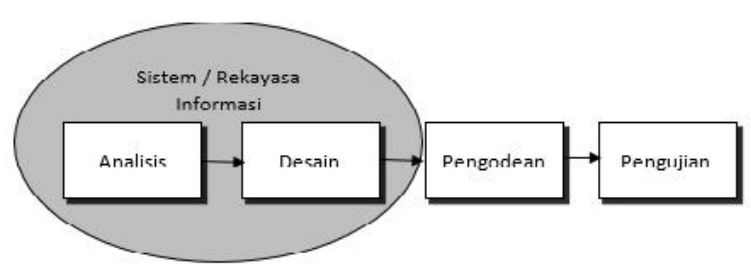

Gambar 1. Model Waterfall

Keterangan Pengembangan sistem model Waterfall, Gambar 2.

a. Analisis

Pada tahap analisis dilakukan komunikasi yang untuk memperoleh informasi tentang perangkat lunak yang diharapkan oleh pengguna dan batasan perangkat lunak. Informasi tersebut diperoleh melalui hasil wawancara, diskusi dan survei langsung dengan pihak PONPES Darussalam Dukuhwaluh.

b. Desain

Tahap desain sistem dilakukan untuk menunjang dalam menentukan perangkat keras (hardware) dan persyaratan sistem yang mendukung dalam mendefinisikan arsitektur sistem keseluruhan seperti model pada sistem pengujian tes, tampilan interface yang disesuaikan dengan user dan fungsi aplikasi pembayaran administrasi santri sesuai kebutuhan yang diinginkan pengguna.

c. Pengkodean

Pada tahap ini dilakukan pengkodean untuk aplikasi pembayaran administrasi santri. Pengkodean menggunakan Microsoft Visual Studio 2012.

d. Pengujian

Pengujian dilakukan dengan 2 pendekatan Alpha Testing dan Beta Testing. Alpha Testing pengujian yang dilakukan untuk menguji fungsioanal sistem menggunakan metode Black box Testing sedangkan, Beta Testing pengujian yang dilakukan kepada pengguna atau User Acceptance Testing Menggunakan Kuesioner (Wahyudi, Utami, \& Arief, 2016). 


\section{HASIL DAN PEMBAHASAN}

\subsection{Analisa}

a. Perencanaan (Planning)

Tahap perencanaan dilakukan dengan mengumpulkan spesifikasi kebutuhan pengguna untuk memahami konteks bisnis pada sistem informasi pembayaran administrasi santri yang akan dibangun dan untuk mendapatkan pandangan output sistem informasi serta fitur dan fungsi utama pada sistem informasi pembayaran Administrasi di PONPES Darussalam Dukuhwaluh. Peneliti menggunakan observasi, wawancara dan dokumentasi untuk mendapatkan spesifikasi kebutuhan pengguna. Tahap ini menciptakan sebuah alur sistem, kemudian PONPES Darussalam Dukuhwaluh memberikan nilai prioritas berdasarkan nilai bisnis fitur atau secara fungsi keseluruhan.

Berdasarkan hasil observasi dan wawancara dapat dijabarkan spesifikasi kebutuhan baik kebutuhan fungsional maupun kebutuhan non fungsional, dokumen yang dibutuhkan serta perancangan DFD sebagai berikut:

1. Identifikasi Kebutuhan Fungsional
(Functional Requirements) Kebutuhan fungsional adalah kebutuhan yang mendeskripsikan layan, fitur, atau fungsi yang disediakan atau diberikan oleh sistem bagi penggunanya sebagai berikut: a) Kebutuhan Masukan (Input)

Kebutuhan masukan yang diperlukan untuk memenuhi implementasi sistem adalah:

1) Data berupa nama pengguna dan kata sandi yang diperlukan pengguna untuk login /masuk sistem.

2) Data pengguna meliputi id petugas, nama petugas, kata sandi, konfirmasi kata sandi, level yang digunkan untuk tingkatan hak akses terhadap sistem.

3) Data santri dan data tagihan santri yang akan dibayarakan oleh santri.

4) Data parameter meliputi data Jenis biaya, Data Jariyah, Data tahun Angkatan, Data Pekerjaan Orangtua, Data Sekolah, data kamar.
5) Data Pengaturan sistem meliputi pengaturan Tahun Angkatan dan pengaturan beban Biaya dibutuhkan untuk menentukan data proses transaksi.

6) Data transaksi pembayaran yang meliputi pembayaran Uang Makan, Syahriyah, listrik (jika santri membawa laptop), Jariyah, Kartu Tanda Santri dan Jas Almamater.

b) Kebutuhan Proses (Process)

Analisis Kebutuhan Proses pada sistem yang akan dibangun terdiri atas:

1) Proses data Pengaturan

2) Proses data pengaturan hanya diberkan kepada admin meliputi pengaturan tahun angkatan, pengaturan beban biaya, Atur koneksi Modem. Untuk melakukan proses pada sistem dibutuhkan atur data tahun angkatan terlebih dahulu supaya sistem memproses data berdasarkan tahun angkatan.

3) Proses pemasukan data santri

4) Proses pemasukan data santri yaitu: NIS, nama, tempat lahir, tanggal lahir, jenis kelamin, no telp, nama orangtua, Pekerjaan, alamat, sekolah, nama kamar, tanggal masuk.

5) Proses pemasukan data Parameter

6) Data parameter meliputi pemasukan data jenis Biaya, data jariyah, data pekerjaan orangtua, data tahun angkatan, data sekolah dan data kamar.

7) Proses transakasi pembayaran santri

8) Proses transaksi pembayaran di PONPES darussalam meliputi pendaftaran santri baru, KTS, jariyah, jas almamater, Uang makan, Syahriyah, dan tambahan listrik (jika santri membawa laptop)

9) Proses data Tagihan pembayaran

10) Pada data tagihan diatur meliputi penentuan santri baru atau santri lama dan penentuan

11) beban tagihan anatara lain hanya dibayarkan sekali meliputi Kartu Tanda Santri, Jariyah, Jas Almamater, dibayarakan tiap bulan meliputi Syahriyah, Uang makan dan tambahan listrik. 
c) Kebutuhan Keluaran (Output)

Kebutuhan keluaran berupa laporan data santri, laporan tagihan santri, dan laporan data pembayaran santri.

\subsection{Perancangan (Design)}

Perancangan perangkat lunak merupakan proses multi langkah yang fokus pada perancangan perangkat lunak termasuk struktur data, arsitektur perangkat lunak, perancangan antar muka, dan prosedur pengkodean. Tahap ini menerjemahkan kebutuhan perangkat lunak dari tahap analisis kebutuhan ke desain agar dapat di implementasikan menjadi sebuah program pada tahap selanjutnya. Beberapa tahapan dalam proses desain meliputi:

\section{1) Perancangan Hak Akses Sistem}

\section{a) Admin}

Admin memegang hak akses penuh terhadap sistem dimana hanya ada satu admin yang dimiliki oleh ketua putra PONPES. Hak akses admin mempunyai wewenang sebagai berikut: Mengolah data santri baru dan lama, Mengolah data parameter meliputi data (jenis biaya, jariyah, pekerjaan orang tua, tahun angkatan, sekolah, dan kamar), Mengolah transaksi pembayaran, Melihat dan mencetak data laporan, Melakukan pengaturan tahun angkatan dan hak akses sistem, Melakukan pengaturan ulang kata sandi, Melakukan pengaturan ulang tampilan gambar utama, Melakukan pengaturan beban tagihan, Mengirim data tagihan pembayaran.

b) Operator

Hak akses operator bisa dimiliki oleh beberapa orang. Dalam hal ini operator diatur oleh admin. Hak akses operator mempunyai wewenang: Mengolah data santri baru dan lama, Mengolah data parameter meliputi data (jenis biaya, jariyah, pekerjaan orang tua, tahun angkatan, sekolah, dan kamar), Mengolah transaksi pembayaran, Mengirim data tagihan pembayaran, Melihat dan mencetak data laporan.

\section{2) Data Flow Diagram (DFD)}

Data Flow Diagram adalah suatu cara yang digunakan untuk menggambarkan aliran data dalam suatu sistem. Beberapa gambaran desain aliran data dalam sistem pembayaran administrasi santri sebagai berikut: Diagram konteks terdiri dari tiga entitas luar dengan keterangan sebagai berikut: Diagram konteks terdiri dari tiga entitas luar dengan keterangan sebagai berikut:

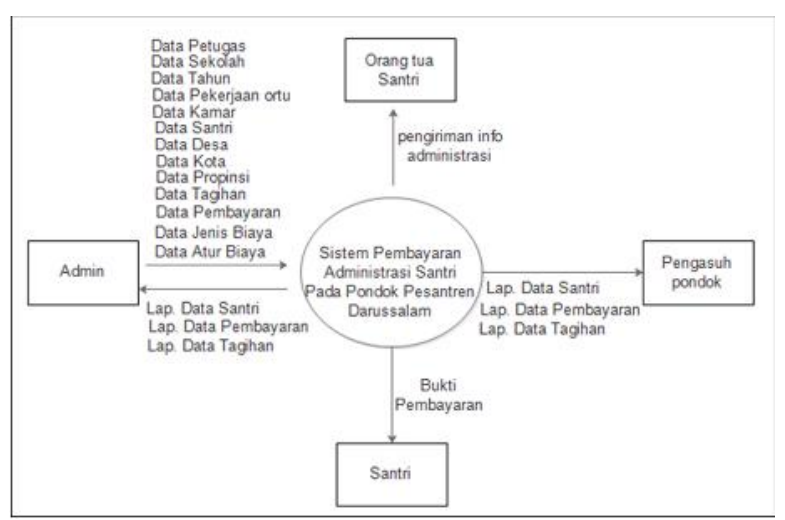

Gambar 2. Diagram Konteks

Keterangan Gambar 2 sebagai berikut:

a. Entitas Admin memiliki hak akses penuh terhadap sistem pembayaran administrasi santri, sehinggga dalam entitas ini bisa mengakses semua menu yang ada dalam sistem.

b. Entitas Pengasuh pondok mempunyai akses dalam melihat seluruh laporan rekap data seperti data santri, pembayaran dan tagihan pembayaran.

c. Entitas Santri sebagai penerima bukti pembayaran, tidak ada hak akses kedalam sistem. 
(b) DFD Level 1

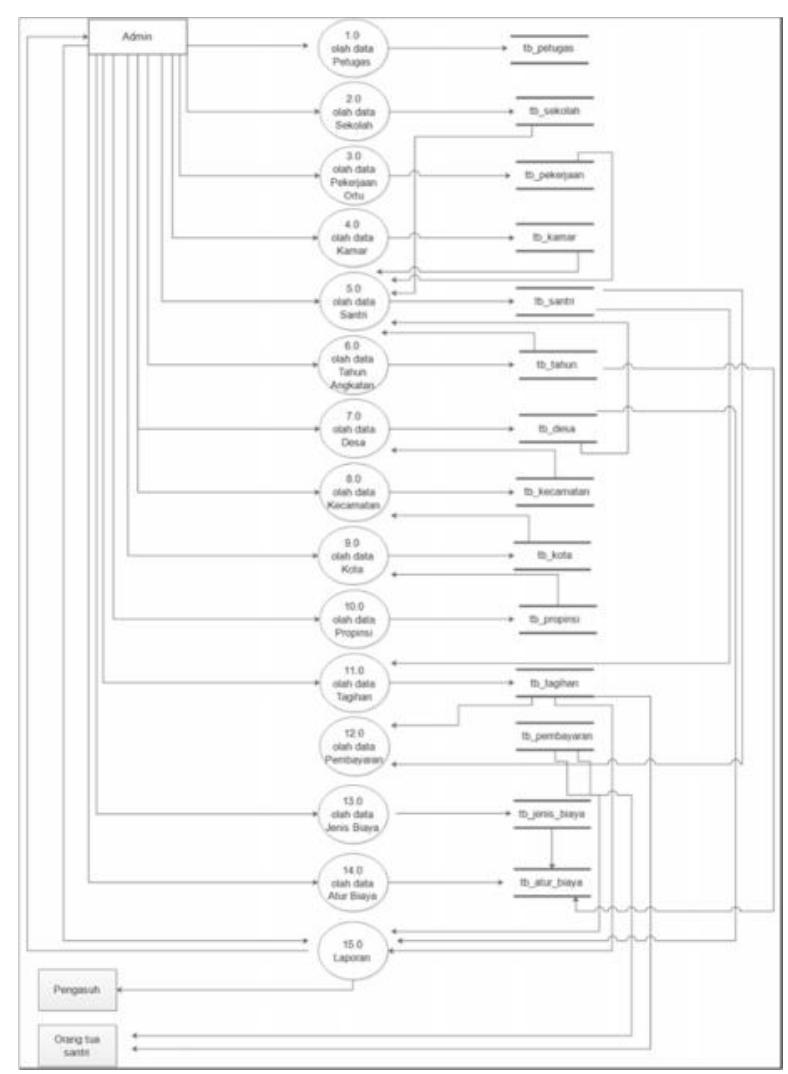

Gambar 3. DFD Level 1

Proses - proses yang terlibat dalam DFD level 1 adalah sebagai berikut:

a. Proses 1.0 yaitu proses olah data petugas. Pada proses ini hanya pengguna yang mempunyai hak akses admin yang bisa menambahakan atau mengurangi data petugas. Data petugas yang sudah diproses akan dimasukan dalam penyimpanan tb_petugas.

b. Proses 2.0 yaitu proses olah data sekolah. Dalam proses ini bisa melakukan input data sekolah. Data sekolah dimasukan sebagai inputan dalam mengolah data santri 5.0.

c. Proses 3.0 yaitu proses olah data pekerjaan orang tua. Dalam proses ini bisa melakukan input data pekerjaan orang tua santri. Data pekerjaan dimasukan sebagai inputan dalam mengolah data santri 5.0.

d. Proses 4.0 yaitu proses olah data kamar. Dalam proses ini bisa melakukan input data kamar santri. Data kamar dimasukan sebagai inputan dalam mengolah data santri 5.0.

e. Proses 5.0 yaitu proses olah data santri. Dalam proses ini bisa melakukan input data santri. Data santri dimasukan sebagai inputan dalam mengolah data laporan diproses 15.0.

f. Proses 6.0 yaitu proses olah data tahun angkatan. Dalam proses ini bisa melakukan input data tahun angkatan santri. Data tahun dimasukan sebagai inputan dalam mengolah data atur biaya 14.0.

g. Proses 7.0 yaitu proses olah data desa. Dalam proses ini bisa melakukan input data desa santri. Data desa dimasukan sebagai inputan dalam mengolah data santri 5.0.

h. Proses 8.0 yaitu proses olah data kecamatan. Dalam proses ini bisa melakukan input data kecamatan santri. Data kecamatan dimasukan sebagai inputan dalam mengolah data santri 5.0.

i. Proses 9.0 yaitu proses olah data kota. Dalam proses ini bisa melakukan input data kota santri. Data kota dimasukan sebagai inputan dalam mengolah data santri 5.0.

j. Proses 10.0 yaitu proses olah data propinsi. Dalam proses ini bisa melakukan input data propinsi santri. Data propinsi dimasukan sebagai inputan dalam mengolah data santri 5.0.

k. Proses 11.0 yaitu proses pengolahan data tagihan. Proses ini melakukan input data tagihan pembayaran santri. Data tagihan dimasukan sebagai inputan dalam mengolah data pembayaran 12.0 dan data laporan proses 15.0.

1. Proses 12.0 yaitu proses olah data pembayaran. Dalam proses ini bisa melakukan input data pembayaran santri. Data pembayaran dimasukan sebagai inputan dalam mengolah data laporan proses 15.0.

m. Proses 13.0 yaitu proses olah data jenis biaya. Dalam proses ini bisa melakukan input data jenis biaya. Data jenis biaya dimasukan sebagai inputan dalam mengolah data atur biaya 14.0. 
n. Proses 14.0 yaitu proses olah data atur biaya. Dalam proses ini bisa melakukan input data atur biaya santri. Dan data yang sudah diproses akan masuk dalam tabel tb_atur_biaya.

o. Proses 15.0 yaitu proses olah data laporan. Dalam proses ini bisa melakukan pembuatan laporan mengenai laporan data santri, tagihan dan pembayaran.

\section{3) Arsitektur SMS Gateway}

Arsitektur SMS Gateway pada Aplikasi

Administrasi Santri pada PONPES

Darussalam Dukuhwaluh mengadaptasi dari penerapan SMS Gateway Poin pelanggaran siswa SMK YPT 1 Purbalingga (Wahyudi \& Aristantia, 2017) yang akan diterapkan pada Gambar 4.

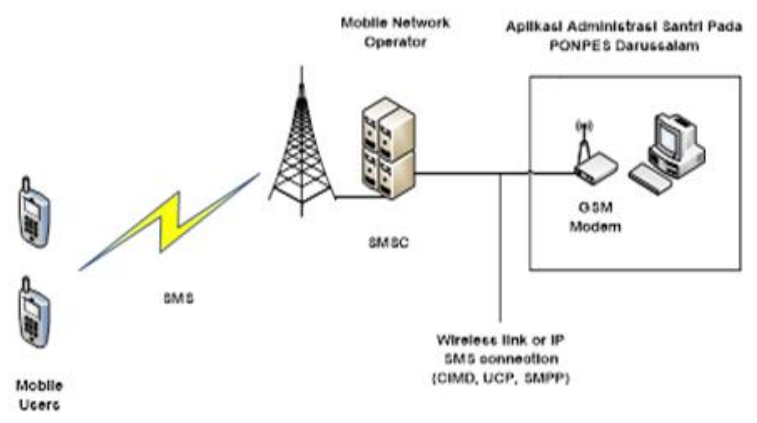

Gambar 4. Arsitektur SMS Gateway pada Aplikasi Administrasi Santri pada PONPES Darussalam Dukuhwaluh

\subsection{Pengkodean}

a. Kode Program Pembayaran Santri

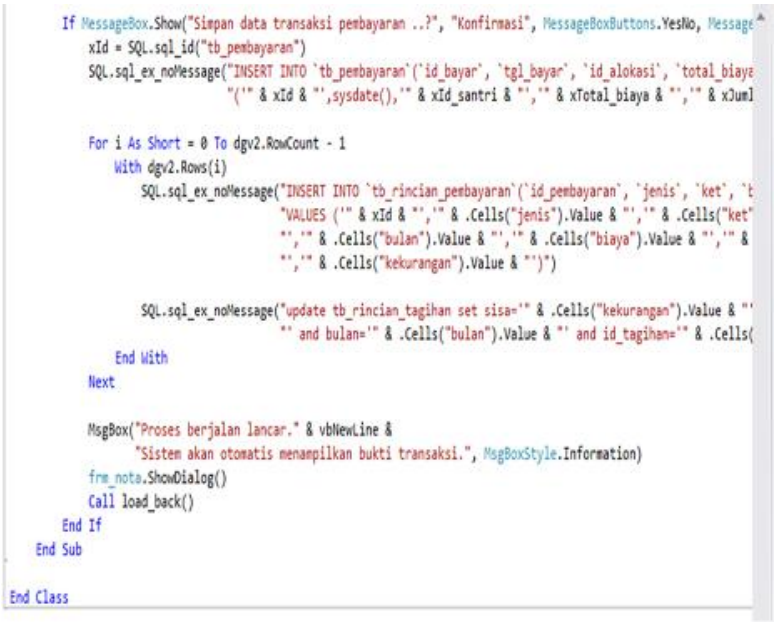

Gambar 5. Kode Program Pembayaran Santri
Pada Gambar 5. baris program diatas berfungsi untuk menyimpan data pembayaran. Pada saat melakukan pembayaran operator memasukan data pembayaran sesuai dengan form pembayaran. Jika pembayaran sudah disimpan maka akan terkoneksi dengan tb_pembayaran, tb_rincian_pembayaran dan tb_rincian_tagihan. Jika pembayaran yang dilakukan hanya menyicil maka akan masuk dalam database tb_rincian_tagihan. Jika pembayaran lunas maka tidak ada tagihan.

b. Implementasi

Berikut beberapa implementasi tampilan user:

1) Form Menu Utama

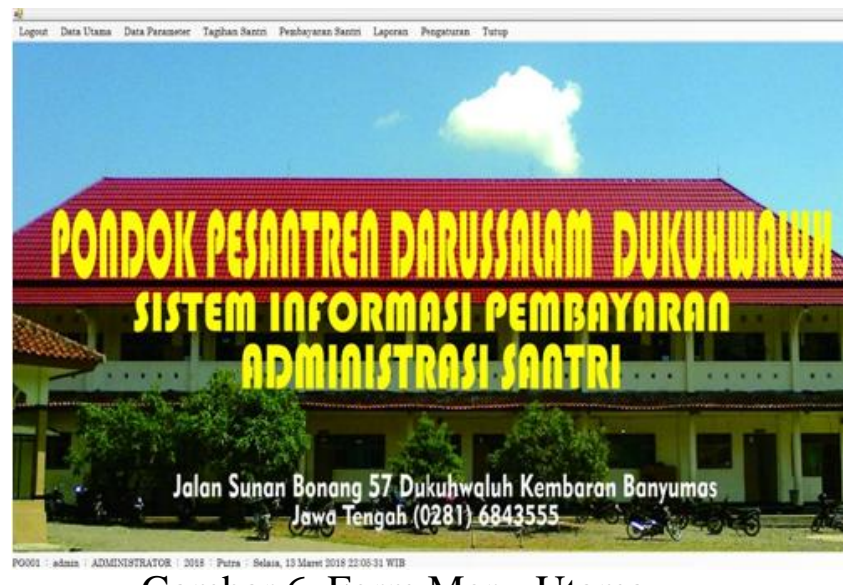

Gambar 6. Form Menu Utama

Keterangan Gambar 6:

a) Form utama digunakan sebagai tampilan utama untuk semua menu yang disajikan dalam aplikasi pembayaran administrasi.

b) Setiap menu yang ada pada form utama terdapat sub menu.

(1) Untuk menu Data Utama terdapat sub menu data petugas dan data santri,

(a) Form Data Santri mempunyai sub menu Form data santri digunakan untuk menambahkan, merubah dan menghapus data santri, sub menu Fungsi cari data digunakan untuk mencari data santri berdasarkan nama santri

(b) Form Data petugas digunakan untuk manambah, merubah, menghapus data petugas yang bisa masuk kedalam aplikasi dan Aturan sistem untuk form petugas adalah 
untuk data admin hanya satu saja, sedangkan untuk operator boleh lebih dari satu.

(2) Untuk menu Data Parameter terdapat sub menu data jenis biaya, data jariyah, data pekerjaan orangtua, data tahun angkatan, data sekolah / kuliah, data kamar.

(a) Form atur tahun angkatan diatur terlebih dahulu setelah melakukan login, karena data tahun angkatan santri menjadikan data menjadi terkelompok berdasarkan tahun angkatan dan Terdapat combo box pilihan tahun angkatan dan tombol proses untuk melanjutkan proses selanjutnya.

(b) Form atur beban biaya digunakan mengatur biaya administrasi santri Terdapat tanggal update sehingga memudahkan petugas ketika akan mengupdate data yang baru

(c) Form jenis biaya digunakan untuk memasukan data jenis - jenis biaya administrasi santri untuk keterangan ada tiga pilihan yaitu sekali berarti biaya dikenakan satu kali ketika santri pertama masuk, bulanan berarti dikenakan biaya tiap bulan dan tahunan dikenakan biaya pada acara tahunan seperti haflah.

(d) Form jariyah digunakan untuk memasukan data jariyah atau iuran sukarela ketika santri pertama masuk pondok pesantren.

(e) Form pekerjaan orangtua / wali digunakan untuk memasukan data pekerjaan orangtua santri.

(f) Form Tahun angkatan digunakan untuk memasukan data tahun angkatan santri.

(g) Form Sekolah / kuliah digunakan untuk memasukan data sekolah santri.

(h) Form Kamar digunakan untuk memasukan data kamar santri.

(3) Untuk Menu Pembayaran santri, menu Laporan terdapat sub menu laporan data santri dan laporan data pembayaran.

(a) Form pembayaran santri digunakan untuk melakukan transaksi pembayaran santri. Ketika akan memasukan data kita hanya perlu mencarinya di link cari data santri nanti akan otomatis data santri terisi. Pada rincian tagihan di isi tagihan apa saja yang akan dibayarkan santri, tombol rincian untuk memasukan data tagihan ke kolom tagihan.

(b) Form Kwitansi pembayaran digunakan untuk mencetak transaksi pembayaran (c) untuk mengaktifkan proses SMS gateway untuk mengirim SMS ke no telp orang tua santri.

(4) Untuk setiap menu Laporan, terdapat sub menu laporan Form Laporan Data santri, Laporan Data Pembayaran, Laporan Data Tagihan

(a) Form laporan data santri digunakan untuk membuat laporan santri pilihan berdasarkan tahun dan nama kamar santri.

(b) Form laporan data pembayaran santri digunakan untuk membuat laporan pembayaran, pilih berdasarkan periode tanggal awal dan periode akhir yang ditentukan oleh petugas.

(c) Form laporan data tagihan digunakan untuk membuat laporan tagihan kepada orang tua santri. Pada form ini terdapat button aktifkan modem digunakan

(5) Menu Pengaturan terdapat sub menu Atur tahun angkatan dan Atur beban biaya. Menu Tutup digunakan untuk menutup aplikasi.

2) Form Atur Beban Biaya

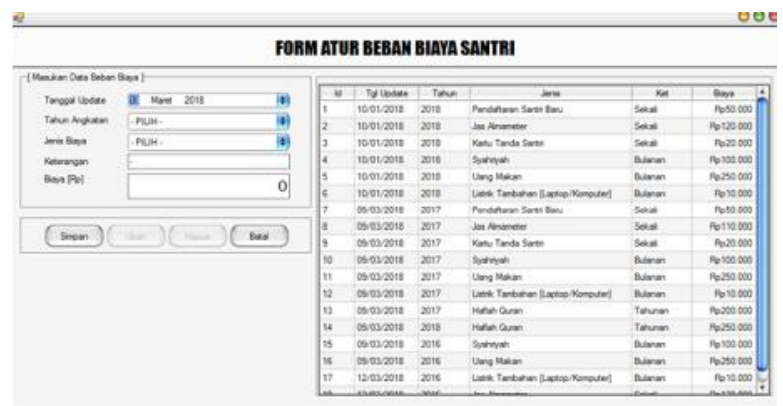

Gambar 7. Form Atur beban biaya

Keterangan Gambar 7:

a) Form atur beban biaya digunakan mengatur biaya administrasi santri.

b) Terdapat tanggal update sehingga memudahkan petugas ketika akan mengupdate data yang baru.

c) Terdapat tombol simpan untuk menyimpan data, tombol ubah digunakan untuk merubah data, tombol hapus untuk menghapus data, tombol batal untuk membatalkan perintah.

2) Form Laporan Data Tagihan 


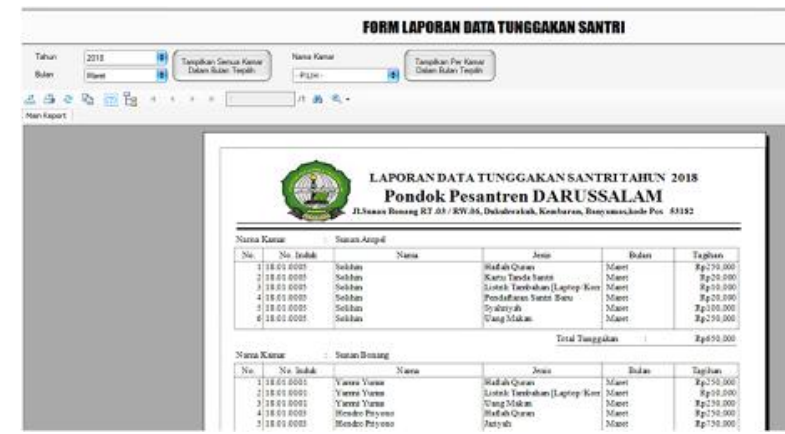

Gambar 8. Form Laporan data Tagihan

Keterangan Gambar 8 :

a) Form laporan data tagihan digunakan untuk membuat laporan tagihan kepada orang tua santri.

b) Pada form ini terdapat button aktifkan modem digunakan untuk mengaktifkan proses SMS Gateway untuk mengirim SMS ke no telp orang tua santri.

\subsection{Pengujian}

Pengujian dilakukan dengan dua pendekatan Alpha Testing dan Beta Testing berikut uraiannya

a. Pengujian Alpha

Rencana pengujian Alpha yang akan dilakukan adalah menggunakan metode Black Box. pengujian berisi tentang pengujian fungsional sistem (Wahyudi, Utami, \& Arief, 2016) diantaranya sebagai berikut :

Tabel 2. Tabel Rencana Pengujian

\begin{tabular}{|c|c|c|c|c|}
\hline \multirow[b]{2}{*}{ No } & \multirow[b]{2}{*}{ Kelas Uji } & \multicolumn{3}{|c|}{ Jenis } \\
\hline & & Butir Uji & $\begin{array}{l}\text { Peng } \\
\text { ujian }\end{array}$ & Status \\
\hline 1 & Login & $\begin{array}{l}\text { Verifikas } \\
\text { i data }\end{array}$ & $\begin{array}{c}\text { Black } \\
\text { box }\end{array}$ & Sukses \\
\hline 2 & $\begin{array}{l}\text { Master } \\
\text { data }\end{array}$ & $\begin{array}{l}\text { Tambah } \\
\text { data }\end{array}$ & $\begin{array}{c}\text { Black } \\
\text { box }\end{array}$ & Sukses \\
\hline & Petugas & $\begin{array}{l}\text { Ubah } \\
\text { data } \\
\text { Hapus } \\
\text { data }\end{array}$ & & \\
\hline
\end{tabular}

\begin{tabular}{|c|c|c|c|c|}
\hline 3 & $\begin{array}{l}\text { Master } \\
\text { data Santri }\end{array}$ & $\begin{array}{l}\text { Tambah } \\
\text { data } \\
\text { Ubah } \\
\text { data } \\
\text { Hapus } \\
\text { data }\end{array}$ & $\begin{array}{l}\text { Black } \\
\text { box }\end{array}$ & Sukses \\
\hline 4 & $\begin{array}{l}\text { Master } \\
\text { data Atur } \\
\text { biaya }\end{array}$ & $\begin{array}{l}\text { Tambah } \\
\text { data } \\
\text { Ubah } \\
\text { data } \\
\text { Hapus } \\
\text { data }\end{array}$ & $\begin{array}{c}\text { Black } \\
\text { box }\end{array}$ & Sukses \\
\hline 5 & $\begin{array}{l}\text { Master } \\
\text { data Jenis } \\
\text { biaya }\end{array}$ & $\begin{array}{l}\text { Tambah } \\
\text { data } \\
\text { Ubah } \\
\text { data } \\
\text { Hapus } \\
\text { data }\end{array}$ & $\begin{array}{c}\text { Black } \\
\text { box }\end{array}$ & Sukses \\
\hline 6 & $\begin{array}{l}\text { Master } \\
\text { data Jariya } \\
\text { h }\end{array}$ & $\begin{array}{l}\text { Tambah } \\
\text { data } \\
\text { Ubah } \\
\text { data } \\
\text { Hapus } \\
\text { data }\end{array}$ & $\begin{array}{c}\text { Black } \\
\text { box }\end{array}$ & Sukses \\
\hline 7 & $\begin{array}{l}\text { Master } \\
\text { data } \\
\text { Pekerjaan } \\
\text { orangtua }\end{array}$ & $\begin{array}{l}\text { Tambah } \\
\text { data } \\
\text { Ubah } \\
\text { data } \\
\text { Hapus } \\
\text { data }\end{array}$ & $\begin{array}{c}\text { Black } \\
\text { box }\end{array}$ & Sukses \\
\hline 8 & $\begin{array}{l}\text { Master } \\
\text { data Tahun } \\
\text { angkatan }\end{array}$ & $\begin{array}{l}\text { Tambah } \\
\text { data } \\
\text { Ubah } \\
\text { data }\end{array}$ & $\begin{array}{c}\text { Black } \\
\text { box }\end{array}$ & Sukses \\
\hline
\end{tabular}




\begin{tabular}{|c|c|c|c|c|}
\hline & & $\begin{array}{c}\text { Hapus } \\
\text { data }\end{array}$ & & \\
\hline 9 & $\begin{array}{l}\text { Master } \\
\text { data } \\
\text { Sekolah }\end{array}$ & $\begin{array}{l}\text { Tambah } \\
\text { data } \\
\text { Ubah da } \\
\text { ta } \\
\text { Hapus d } \\
\text { ata }\end{array}$ & $\begin{array}{c}\text { Black } \\
\text { box }\end{array}$ & Sukses \\
\hline 10 & $\begin{array}{l}\text { Master } \\
\text { data } \\
\text { Kamar }\end{array}$ & $\begin{array}{l}\text { Tambah } \\
\text { data } \\
\text { Ubah } \\
\text { data } \\
\text { Hapus } \\
\text { data }\end{array}$ & $\begin{array}{c}\text { Black } \\
\text { box }\end{array}$ & Sukses \\
\hline 11 & $\begin{array}{l}\text { Master } \\
\text { data } \\
\text { Pembayar- } \\
\text { an }\end{array}$ & $\begin{array}{l}\text { Simpan } \\
\text { data }\end{array}$ & $\begin{array}{c}\text { Black } \\
\text { box }\end{array}$ & Sukses \\
\hline
\end{tabular}

b. Pengujian Beta Testing

Pengujian yang dilakukan dengan membagi kuesioner dan mencobakan sistem kepada pengurus PONPES darussalam. bertujuan untuk melihat kualitas sistem apakah sudah sesuai dengan kebutuhan pengguna yaitu bendahara di PONPES darussalam. Pengujian ini juga dilakukan untuk mendapatkan tanggapan dari pengguna aplikasi tentang kelengkapan informasi dan fitur pada aplikasi (Purwanto \& Wahyudi, 2018). Berikut kuesioner pengujian sistem pada Tabel 3.

Tabel 3. Kuesioner Pengujian Sistem

\begin{tabular}{|c|c|c|c|c|c|c|}
\hline \multirow{2}{*}{ No } & \multirow{2}{*}{ Aspek - Aspek } & \multicolumn{5}{|c|}{ Penilaian } \\
\hline & & ss & $\mathrm{s}$ & $\mathrm{rr}$ & ts & sts \\
\hline 1 & $\begin{array}{l}\text { Apakah } \\
\text { tampilan } \\
\text { aplikasi ini }\end{array}$ & 3 & & & & \\
\hline
\end{tabular}

menarik.

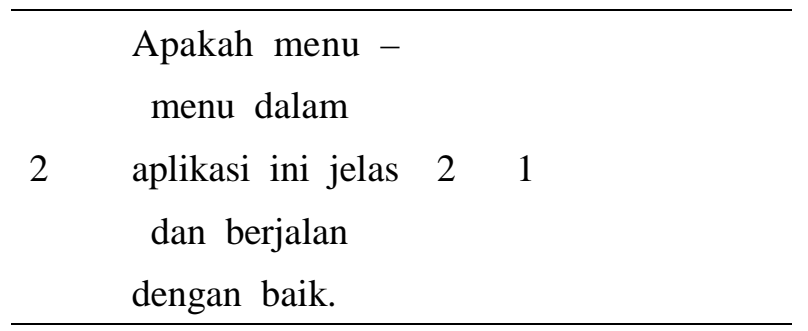

Fitur yang

3 diberikan sesuai 3

kebutuhan.

\begin{tabular}{|c|c|c|c|c|}
\hline 4 & $\begin{array}{l}\text { Aplikasi } \\
\text { pembayaran a } \\
\text { dministrasi } \\
\text { mudah dioperasi } \\
\text { kan. }\end{array}$ & 1 & 2 & \\
\hline 5 & $\begin{array}{l}\text { Apakah SMS } \\
\text { Gateway pada } \\
\text { aplikasi yang di } \\
\text { gunakan sudah } \\
\text { membantu. }\end{array}$ & 2 & 1 & \\
\hline 6 & $\begin{array}{l}\text { Sistem } \\
\text { informasi } \\
\text { pembayaran } \\
\text { administrasi } \\
\text { santri layak } \\
\text { digunakan untuk } \\
\text { transaksi } \\
\text { pembayaran } \\
\text { administrasi. }\end{array}$ & 3 & & \\
\hline \multicolumn{2}{|c|}{ Jumlah } & 14 & 40 & $0 \quad 0$ \\
\hline
\end{tabular}


Tabel 4. Tabel Presentase Nilai

\begin{tabular}{cl}
\hline Jawaban & Keterangan \\
\hline $0 \%-19,99 \%$ & $\begin{array}{l}\text { Sangat (Tidak Setuju, Bur } \\
\text { uk atau Kurang sekali) }\end{array}$ \\
\hline $20 \%-39,99 \%$ & $\begin{array}{l}\text { Tidak Setuju atau Kurang } \\
\text { Baik }\end{array}$ \\
\hline $40 \%-59,99 \%$ & Cukup atau Netral \\
\hline $60 \%-79,99 \%$ & Setuju, Baik atau Suka \\
\hline $80 \%-100 \%$ & Sangat (Setuju, Baik, Suk
\end{tabular}

a)

Untuk menghasilkan interpretasi, menggunakan rumus skala Likert:

$$
\text { Rumus Index \% }=\frac{\text { Total Skor x } 100 \%}{Y}
$$

Keterangan:

Total Skor $=$ Jumlah responden $\mathrm{x}$ bobot nilai likert

$\mathrm{Y}=$ Jumlah total Responden $\mathrm{x}$ skor tertinggi likert.

Tabel Presentasi Nilai Jumlah responden ada 3 orang dengan jumlah pertanyaan ada 6 pertanyaan. Jumlah nilai tertinggi 5, nilai terendah 1. Dari hasil perhitungan kuesioner didapatkan presentase sebagai berikut:

a. Total Skor $=($ Total pemilih terbanyak $\mathrm{x}$ Skor) + (total terendah $\mathrm{x}$ skor)

Total Skor $=(14 \times 5)+(4 \times 4)$

Total Skor $\quad=86$

b. Skor tertinggi $=$ (nilai tertinggi $\mathrm{x}$ jumlah pertanyaan $\mathrm{x}$ jumlah responden)

$\begin{aligned} & =(5 \\ \text { Skor tertinggi } & =90\end{aligned}$

c. Rumus index $\%=$ total skor / skor tertinggi $\mathrm{x} 100 \%$

$$
\begin{aligned}
& =(86 / 90) \times 100 \% \\
& =95,5 \%
\end{aligned}
$$

Tabel 5. Hasil Presentasi Kuesioner

\begin{tabular}{ll}
\hline Pertanyaan ke- & Presentase \\
\hline 1 & $100 \%$ \\
\hline 2 & $93,3 \%$ \\
\hline 3 & $100 \%$ \\
\hline 4 & $88,5 \%$ \\
\hline 5 & $93,3 \%$ \\
\hline 6 & $100 \%$ \\
\hline
\end{tabular}

Berdasarkan hasil kuesioner dapat diambil kesimpulan bahwa Sistem informasi pembayaran administrasi santri sudah dapat di terima dan di implementasikan pada PONPES Darussalam.

\section{KESIMPULAN DAN SARAN}

\subsection{Kesimpulan}

Berdasarkan hasil dari peneltian yang telah dilakukan di PONPES Darussalam Dukuhwaluh sebagai berikut:

a. Aplikasi pembayaran administrasi santri berbasis Desktop untuk membantu bendahara dalam pengolahan administrasi pada PONPES Darussalam yang terintegrasi dengan SMS Gateway, membantu dalam penyampaian informasi berupa pembayaran dan tunggakan administrasi santri kepada orang tua, sehingga dapat terkontrol dengan baik.

b. Dari hasil pengujian Alpha Testing yang telah dilakukan menggunakan metode Blackbox testing hasilnya semua fungsional sistem berjalan sesuai yang diharapkan dan hasil Beta testing dengan membagi kuesioner kepada pengurus PONPES menunjukan rata-rata indeks dari responden sebesar 95,5\% termasuk dalam kategaori sangat setuju. Sehingga dapat di simpulkan bahwa Sistem informasi pembayaran administrasi santri dapat di implementasikan pada PONPES Darussalam Dukuhwaluh.

\subsection{Saran}

Untuk penelitian selanjutnya di saran kan pada penelitian selanjutnya agar 
menggunakan teknologi berbasis Website sehingga dapat di akses dimana saja.

\section{DAFTAR PUSTAKA}

Anshori, M., Yosi, A., Fibrian, I. D., \& Zainal, M. (2008). Upaya Peningkatan Pelayanan Administrasi Kependudukan Menggunakan Teknologi Informasi : Rancang Bangun Sistem Informasi di Desa Sumbermulyo Kecamatan Jogoroto Kabupaten Jombang. Jurnal Ilmiah Teknologi Sistem Informasi, 2, 51-59. Retrieved from http://www.journal.unipdu.ac.id/index. php/register/article/view/547

Lutfi, A. A., \& Wahyudi, R. (2017). Aplikasi Tracer Study Berbasis Website Responsive Pada Fakultas Pertanian Universitas Jendral Soedirman. Majalah Ilmiah INTI (Informasi Dan Teknologi Ilmiah), 13, 125-132.

Purwanto, T., \& Wahyudi, R. (2018). Rancang Bangun Aplikasi Penjualan Berbasis Web Terintegrasi Barcode. Indonesian Journal on Networking and Security, 7(3), 3-7.

Rosa, A.S., dan Shalahudin, M. 2013, Rekayasa Perangkat Lunak Terstruktur Dan Berorientasi Objek. Bandung: Informatika Bandung.

Rudiyanto, Arif. 2014. Analisis dan Perancangan Sistem Informasi Administrasi Santri Berbasis Web Studi Kasus Pada PONPES Addainuriyah 2 Semarang. Diambil dari https://media.neliti.com/media/publicat ions/207561-analisis-dan-perancangansistem-informas.pdf

Saleh, Taufik. 2017. "Sistem Informasi Administrasi Keuangan Ma Ibrahimy Secang Kalipuro Banyuwangi”. Volume 3 No.1.
Aplikasi Pengolahan Data Pelanggaran Ssiswa Pada SMK Yayasan Pendidikan Teknologi 1 Purbalinggau Terintegrasi Dengan SMS Gateway. Telematika, 10(2), 62-75.

Wahyudi, R., Utami, E., \& Arief, M. R. (2016). Sistem Pakar E-Tourism Pada Dinas Pariwisata D.I.Y Menggunakan Metode Forward Chaining, 17(2), 6775 .

Wahyudi, R., \& Aristantia, A. D. (2017). 